\title{
ANALISIS KEMAMPUAN PEMECAHAN MASALAH MATEMATIKA SISWA KELAS XI IPS I IMOGIRI DENGAN MODEL PEMBELAJARAN MISSOURI MATHEMATICS PROJECT (MMP) BERDASARKAN PENDEKATAN GAYA BELAJAR KOLB
}

\author{
Muhammad Irfan Rumasoreng ${ }^{1)}$ Meta Mahayati ${ }^{2)}$, \\ Prodi Pendidikan Matematika UMBY-Yogyakarta ${ }^{1)}$, Universitas Mercu Buana Yogyakarta ${ }^{2)}$ \\ irfanlaturumasoreng@gmail.com ${ }^{l)}$ metamahayati96@gmail.com ${ }^{2),}$
}

\begin{abstract}
Abstrak: Penelitian ini bertujuan untuk menganalisa klasifikasi gaya belajar siswa berdasarkan gaya belajar Kolb dan mendeskripsikan hasil analisa kemampuan pemecahan masalah siswa untuk setiap gaya belajar pada model pembelajaran Missouri Mathematics Project. Jenis penelitian ini adalah penelitian deskriptif dengan menggunakan mixed methods. Subjek penelitian ini adalah siswa kelas XI IPS 1 SMA Negeri 1 Imogiri tahun penelitian 2017/2018 yang berjumlah 27 siswa. Pengumpulan data menggunakan angket gaya belajar Kolb, tes kemampuan pemecahan masalah, dan pedoman wawancara. Seluruh siswa kelas XI IPS 11Imogiri dipetakan tipe gaya belajarnya dengan menggunakan angket gaya belajar Kolb. Data kemampuan pemecahan masalah dianalsis dari hasil tes kemampuan pemecahan masalah kemudian dilakukan triangulasi dengan data wawancara. Subjek wawancara terdiri dari 8 yang terbagi kedalam 2 siswa untuk masing-masing tipe gaya belajar. Analisis data kuantitatif dengan mengkategorikan gaya belajar. Analisis kualitatif dilakukan dengan tahap-tahap reduksi data, penyajian data, dan menarik kesimpulan. Hasil penelitian menunjukkan bahwa: 1) Gaya belajar Diverger paling banyak jumlahnya di kelas XI IPS 1,2) Siswa dengan gaya belajar Konverger, Diverger, dan Akomodator mampu memahami masalah, merencanakan langkah penyelesaian, melaksanakan rencana penyelesaian dan menarik kesimpulan dengan baik. Siswa dengan gaya belajar Asimilator mampu melaksanakan tahap memahami masalah, merencanakan langkah penyelesaian dan melaksanakan rencana penyelesaian dengan baik, dan dinilai cukup dalam menarik kesimpulan.
\end{abstract}

Kata Kunci: Kemampuan Pemecahan Masalah, Missouri Mathematics Project, Gaya Belajar Kolb

\section{ANAL YSIS OF MATH PROBLEM SOLVING ABILITY GRADE 11 IPS 1 STUDENT'S ON LEARNING OF MISSOURI MATHEMATICS PROJECT (MMP) BASED ON KOLB LEARNING STYLE}

\begin{abstract}
The research aims to invertigate classification based on student's learning style of class 11 IPS 1 by using Kolb learning style and to describe the result of analysis on problem solving ability for each learning style on Missouri Mathematics Project learning model. The type of this research is descriptive research using mixed methods. The subjects of the study were 27 students of class 11 IPS 1 SMA N 1 Imogiri academic year 2017/2018. Data collection involve several techniques such as Kolb's learning style questuonnaire, problem-solving test, and interview guidance. All student of class 11 IPS 1 identified their type of learning style by using Kolb learning style questionnaire. The result of problem solving analysis were then triangulated with interview result. Eight interview subject were devided into two students for each type of learning styles. Qualitative analysis was performed with data reduction phase, data presentation, and conclussion. The result show that:1) Diverger learning style were dominant in class 11 IPS 1, 2) Students with Converger, Diverger, and Accomodator learning style are able to understand the problem, plan problem solving steps, carry out problem solving plan and draw conclusions well. Students with Asimilator learning style are able to perform problem identification, plan properly, and evaluate fair on drawing conclussion.
\end{abstract}

Keywords: Problem Solving Abilities, Missouri Mathematics Project, Kolb Learning Style 
Matematika adalah ilmu asbtrak yang materinya bersifat terstruktur dan saling berhubungan antar materi satu dengan materi lainnya. Dalam kurikulum KTSP dinyatakan bahwa matematika perlu diberikan kepada semua peserta didik mulai dari sekolah dasar untuk membekali kemampuan berpikir kritis, analistis, sistematis, kritis, dan kreatif, serta kemampuan bekerjasama (BSNP, 2006: 387).

Pemecahan masalah adalah komponen yang sangat penting dalam pelaksanaan pengajaran pendidikan matematika di sekolah, fakta menunjukkan pentingnya keterampilan ini dalam kehidupan sehari-hari maupun di dunia kerja dalam menyelesaikan masalah secara efisien. Di dalam beberapa penelitian menunjukkan bahwa siswa sering melibatkan dirinya dengan tugas-tugas ini. (García, Rodríguez, González-Castro, González-Pienda, \& Torrance, 2016; Silver, Ghousseini, Gosen, Charalambous, 2005)

Badan Standar Nasional Pendidikan (BSNP) (2006: 388) menjelaskan bahwa tujuan pembelajaran matematika dalam KTSP untuk satuan pendidikan menengah atas salah satunya adalah agar siswa mampu memecahkan masalah yang meliputi kemampuan memahami masalah, merancang model matematika, menyelesaikan model dan menafsirkan solusi yang diperoleh. NTCM (Effendi, 2012: 2) menetapkan lima standar kemampuan matematis yang harus dimiliki oleh siswa, salah satunya adalah kemampuan pemecahan masalah (problem solving).

Berdasarkan uraian di atas, kemampuan pemecahan masalah siswa sangat perlu dikembangkan dalam mempelajari matematika. Meskipun kemampuan pemecahan masalah merupakan aspek penting, namun masih banyak siswa yang lemah dalam hal pemecahan masalah matematika. Berdasarkan hasil tes PISA pada tahun 2012 masih terlihat kelemahan kemampuan pemecahan masalah matematika siswa (Wulandari \& Jailani, 2015: 194), berikut hasil tersebut yaitu 78\%, $25 \%$ di level 2,10\% siswa di level 3, kurang dari 5\% di level 4, dan kurang dari $1 \%$ di level 5 dan 6, hal ini menempatkan Indonesia berada di peringkat 64 dari 65 negara.

Hasil survei TIMSS tahun 2015 (NCES, 2016: 11) menerangkan bahwa rata-rata prestasi matematika di Indonesia sebesar 397 masih di bawah standar TIMSS yaitu 500. Hasil survei PISA dan TIMSS menunjukkan bahwa kemampuan pemecahan masalah matematika siswa di Indonesia masih kurang.

Penulis telah melakukan prapenelitian di Kelas XI IPS 1 Imogri saat kegiatan PPL II di SMA Negeri 1 Imogiri dan menemukan bahwa kemampuan pemecahan masalah matematika siswa masih tergolong kurang.

Begitu pentingnya pemecahan masalah matematika dalam pembelajaran matematika, maka pendidik tentu harus mengusahakan agar siswa dapat mencapai hasil yang optimal dalam menguasai keterampilan pemecahan masalah. Dalam Fauziah dan Sukasno (2015:11) mengemukakan bahwa hasil belajar siswa terutama pada kemampuan pemecahan masalah matematika siswa di sekolah dimungkinkan karena proses pembelajarannya lebih berkonsentrasi pada latihan soal yang bersifat prosedural dan mekanistik yang menjadikan siswa tidak terlibat aktif dalam menggali ide atau konsep secara bermakna dan hanya menerima ilmu pengetahuan yang bersifat hafalan saja. Dengan demikian diperlukan salah satu model pembelajaran yang tepat dan inovatif dalam pembelajaran matematika yang menjadikan siswa menjadi aktif untuk mengemukakan ide selama proses pemecahan masalah dalam sebuah kelompok. Salah satu model pembelajaran yang dapat digunakan adalah model pembelajaran Missouri Mathematics Project (MMP).

Savitri et al (2013: 33) menjelaskan bahwa model pembelajaran Missouri Mathematics Project efektif untuk meningkatkan kemampuan pemecahan masalah matematika siswa. Model pembelajaran Missouri Mathematics Project (MMP) merupakan 
suatu program yang didesain untuk membantu guru dalam hal efektivitas penggunaan latihanlatihan agar siswa mencapai peningkatan yang luar biasa (Ansori, et al, 2015: 50). Efektivitas penggunaan latihan-latihan soal sangat diharapkan menjadikan siswa terbiasa dalam menyelesaikan permasalahan matematika sehingga kemampuan pemecahan masalah siswa meningkat.

Selain model pembelajaran, gaya belajar adalah salah satu variabel yang bersangkutan langsung dengan cara siswa memahami pelajaran di sekolah. Gaya belajar siswa tentunya berbeda antara satu dengan yang lain. Oleh sebab itu, sangat penging bagi guru mengetahui gaya belajar siswa agar membantu guru dalam melaksanakan pembelajaran di kelas.

Perbedaan gaya belajar siswa untuk setiap individu berdasarkan pengalaman belajar adalah gaya belajar Kolb. Gaya belajar Kolb meliputi gaya belajar diverger (diverger), assimilating (asimilasi), converging (konverger) dan accommodating (akomodator).

Tujuan penelitian ini adalah untuk menganalisa dan mengidentifikasi gaya belajar siswa kelas XI IPS 1 dan mendeskripsikan kemampuan pemecahan masalah matematika siswa untuk setiap tipe gaya belajar siswa pada model pembelajaran Missouri Mathematics Project.

\section{METODE PENELITIAN}

\section{Jenis \& Desain Penelitian}

Jenis penelitian ini adalah penelitian deskriptif yang menggunakan metode kuantitatif dan kualitatif (mixed methods) dalam mengumpulkan, menganalisa, dan menggabungkan data. Metode penelitian kombinasi (mixed methods) adalah pendekatan dalam penelitian yang mengkombinasikan atau menghubungkan antara metode penelitian kuantitatif dan kualitatif.

Desain penelitian berupa concurrent embedded design yang menggunakan pendekatan kuantitatif dan kualitatif secara stimulan/bersama-sama (atau sebaliknya), tetapi berbeda dalam pembobotan. Pada metode ini terdapat metode primer dan metode sekunder.

Penelitian ini menggunakan data kualitatif sebagai metode primer yaitu untuk mengetahui analisis kemampuan pemecahan masalah siswa kelas XI IPS 1. Metode kuantitatif digunakan tipe gaya belajar siswa sebagai data sekunder untuk mendukung adanya data primer. Dalam analisisnya, dilakukan metode kuantitatif dilakukan terlebih dahulu dan metode kualitatif dilakukan setelah dilakukan analisis secara kuantitatif.

\section{Tempat dan Waktu Penelitian}

Penelitian ini dilaksanakan di SMA Negeri 1 Imogiri, Jalan Imogiri km 14, Wukirsari, Imogiri, Bantul pada 1 Maret - 30 April 2018 semester genap tahun pelajaran 2017/2018.

\section{Subjek Penelitian}

Sumber data penelitian ini ialah siswa kelas XI IPS 1 SMA Negeri 1 Imogiri tahun pelajaran 2017/2018 yang berjumlah 27 siswa. Keseluruhan siswa merupakan subjek angket gaya belajar serta subjek tes kemampuan pemecahan masalah, sedangkan delapan siswa lainnya merupakan subjek wawancara kemampuan pemecahan masalah.

Subjek penelitian adalah semua siswa yang mengikuti pembelajaran Missouri Mathematics Project selama 3 kali pertemuan dengan materi turunan. Pemilihan subjek wawancara dilakukan dengan menggunakan teknik purposive sampling. Subjek wawancara dipilih masing-masing dua siswa untuk tiap gaya belajar, sehingga total keseluruhan subjek wawancara kemampuan pemecahan masalah adalah delapan.

\section{Teknik Pengumpulan Data}

Teknik Pengumpulan Data secara Kuantitatif 
Teknik pengumpulan data secara kuantitatif diperoleh melalui angket KSLI (Kolb Learning Style Inventory) dan tes kemampuan pemecahan masalah.

Teknik Pengumpulan Data Kualitatif

Teknik pengumpulan data secara kualitatif diperoleh melalui dokumentasi, RPP yang memuat model pembelajaran Missiouri Mathematics Project, lembar observasi model pembelajaran dan wawancara.

\section{Instrumen Penelitian}

Instrumen penelitian ini berupa : 1) Angket gaya belajar Kolb dari website Miami University yang terdiri dari 48 pertanyaan; 2) Tes kemampuan pemecahan masalah yang terdiri atas 3 soal dengan materi turunan fungsi; 3) Rencana Pelaksanaan Pembelajaran (RPP) yang dibuat berdasarkan KTSP dengan metode pembelajaran menggunakan Missouri Mathematics Project dengan materi fungsi turunan; 4) Lembar observasi keterlaksanaan model pembelajaran; 5) Pedoman wawancara.

\section{Teknik Analisis Data}

Analisis Data Kuantitatif

Analisis data secara kuantitatif digunakan untuk mengkategorikan gaya belajar siswa kelas XI IPS 1 berdasarkan klafisikasi gaya belajar Kolb yang diperoleh dari analisis pada angket gaya belajar Kolb. Penentuan kriteria gaya belajar Kolb didasari dengan menentukan nilai $\mathrm{X}$ dan $\mathrm{Y}$ yang terletak dalam satu koordinat sumbu $\mathrm{X}$ dan sumbu $\mathrm{Y}$.

Sumbu $\mathrm{X}$ dan $\mathrm{Y}$ diplotkan dalam satu koordinat, sehingga terbentuk suatu kecenderungan sebagai berikut: a) Gaya belajar Akomodator terjadi jika $\mathrm{AC}-\mathrm{CE}=\mathrm{Y}$, positif dan $\mathrm{AE}-\mathrm{RO}=\mathrm{X}$, positif; b) Gaya belajar Diverger terjadi jika $\mathrm{AC}-\mathrm{CE}=\mathrm{Y}$, positif dan $\mathrm{AE}-\mathrm{RO}=\mathrm{X}$, negatif; c) Gaya belajar Asimilator terjadi jika $\mathrm{AC}-\mathrm{CE}=\mathrm{Y}$, negatif dan $\mathrm{AE}-\mathrm{RO}=\mathrm{X}$, negatif; d) Gaya belajar Konverger terjadi jika $\mathrm{AC}-\mathrm{CE}=\mathrm{Y}$, negatif dan $\mathrm{AE}-$ $\mathrm{RO}=\mathrm{X}$, positif. Dari definisi di atas maka dapat digambarkan seperti yang terlihat pada Gambar 1.

CE

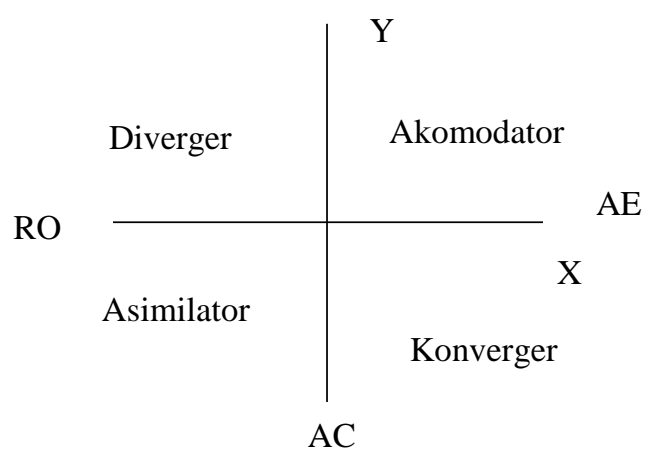

Gambar 1. Ploting Gaya Belajar Kolb dari Koordinat X dan Y

Setelah didapatkan ploting gaya belajar Kolb, diperoleh rumus :

$$
\begin{aligned}
& \mathbf{Y}=\mathbf{A C}-\mathbf{C E} \\
& \mathbf{X}=\mathbf{A E}-\mathbf{R O}
\end{aligned}
$$

Berdasarkan rumus di atas maka gaya belajar Kolb dapat diklasifikasikan seperti yang terlihat Tabel 1. 
Tabel 1. Klasifikasi Tipe Gaya Belajar Kolb

\begin{tabular}{|c|c|c|c|c|}
\hline \multicolumn{2}{|c|}{ Skor } & \multirow{2}{*}{ K } & \multirow{2}{*}{ SK } & \multirow{2}{*}{$\begin{array}{c}\text { Tipe Gaya } \\
\text { Belajar Kolb }\end{array}$} \\
\hline$\underline{Y}$ & $\underline{X}$ & & & \\
\hline+ & + & I & $\mathrm{AE}$ dan $\mathrm{CE}$ & Akomodator \\
\hline+ & - & II & CE dan RO & Diverger \\
\hline - & - & III & $\mathrm{RO}$ dan $\mathrm{AC}$ & Asimilator \\
\hline - & + & IV & $\mathrm{AC}$ dan $\mathrm{CE}$ & Konverger \\
\hline
\end{tabular}

Gaya belajar Diverger terbentuk dari penjumlahan aspek CE \& RO, gaya belajar Asimilator terbentuk dari penjumlahan aspek RO \& AC, gaya belajar Konverger terbentuk dari penjumlahan dari aspek AC \& AE, dan gaya belajar Akomodator terbentuk dari penjumlahan aspek AE \& CE.

Analisis Data Kualitatif

Analisis data adalah proses mencari dan menyusun secara sistematis data yang diperoleh dari tes kemampuan pemecahan masalah, hasil wawancara, dan dokumentasi, dengan cara mengorganisasikan data ke dalam kategori, menjabarkan ke dalam unit-unit, melakukan sintesa, menyusun ke dalam pola, memilih mana yang penting dan yang akan dipelajari, dan membuat kesimpulan sehingga mudah dipahami oleh diri sendiri maupun orang lain. Adapun langkah-langkah analisis data meliputi Reduksi Data, Penyajian data, dan Penarikan Kesimpulan (Sugiyono (2017: 334).

Data Reduction (Reduksi Data)

Reduksi data dalam penelitian ini meliputi kegiatan merangkum, memilih hal-hal yang pokok, memfokuskan pada hal-hal yang penting dan membuang yang tidak perlu. Dengan demikian peneliti akan memperoleh gambaran yang lebih jelas, dan mempermudah peneliti untuk melakukan pengumpulan data selanjutnya. Dalam penelitian ini data yang direduksi adalah hasil wawancara kemampuan pemecahan masalah siswa. Hasil wawancara dirangkum, dipilih hal-hal yang penting, dan membuang hal-hal yang tidak perlu dan tidak berguna sehingga peneliti mendapatkan gambaran yang jelas tentang kemampuan pemecahan masalah siswa dan mempermudah dalam penarikan kesimpulan.

Data Display (Penyajian Data)

Penyajian data dirumuskan untuk menemukan makna dari kata-kata yang diperoleh kemudian disusun secara sistematis dan logis sehingga mudah dipahami. Dalam penelitian kualitatif, penyajian data dapat berbentuk uraian singkat, bagan, hubungan kategori, flowchart, dan sebagainya.

Penyajian data dilakukan dengan memunculkan kumpulan data yang sudah terorganisir dan terkategori yang memungkinkan dilakukan penarikan kesimpulan. Data yang akan disajikan pada penelitian ini berupa hasil tes kemampuan pemecahan masalah siswa, dan hasil wawancara.

Conclution Drawing (Penarikan Kesimpulan)

Penarikan kesimpulan adalah jawaban dari rumusan masalah yang telah dirumuskan sejak awal dan diharapkan merupakan temuan baru yang belum pernah ada. Temuan ini dapat berupa deskripsi atau gambaran suatu objek yang sebelumnya masih samar sehingga diteliti agar menjadi jelas.

Hasil analisis wawancara akan digunakan sebagai triangulasi terhadap hasil analisis tes dan digunakan untuk menganalisa dan mendeskripsikan kemampuan pemecahan masalah siswa dengan masing-masing tipe gaya belajar. Analisis data dilakukan dengan metode perbandingan tetap (The Constant Comparative Metheod). Analisis ini melibatkan perbandingan satu segmen dengan segmen lainnya untuk menentukan persamaan dan perbedaannya. 
Data dikelompokkan bersama-sama dalam dimensi yang sama. Dimensi ini secara tentatif diberikan suatu nama, yang kemudian menjadi kategori. Analisis ini diusahakan agar unsur-unsur empirik yang membedakan satuan-satuan pembanding berada pada data yang sama. Satuan-satuan yang memiliki ciri yang sama diangkat menjadi teori-teori.

\section{HASIL \& PEMBAHASAN \\ Hasil Analisis Data Kuantitatif}

Hasil penelitian kuantitatif pada penelitian dalam ini diperoleh dengan menggunakan angket gaya belajar Kolb. Analisis data dilakukan untuk mengetahui klasifikasi gaya belajar siswa kelas XI IPS 1 di SMA Negeri 1 Imogiri berdasarkan gaya belajar Kolb. Analisis data yang dilakukan dengan menggunakan program Microsoft Excel 2016.

Adapun pengelompokan data dalam diagram kartesius akan disajikan pada Gambar 2.

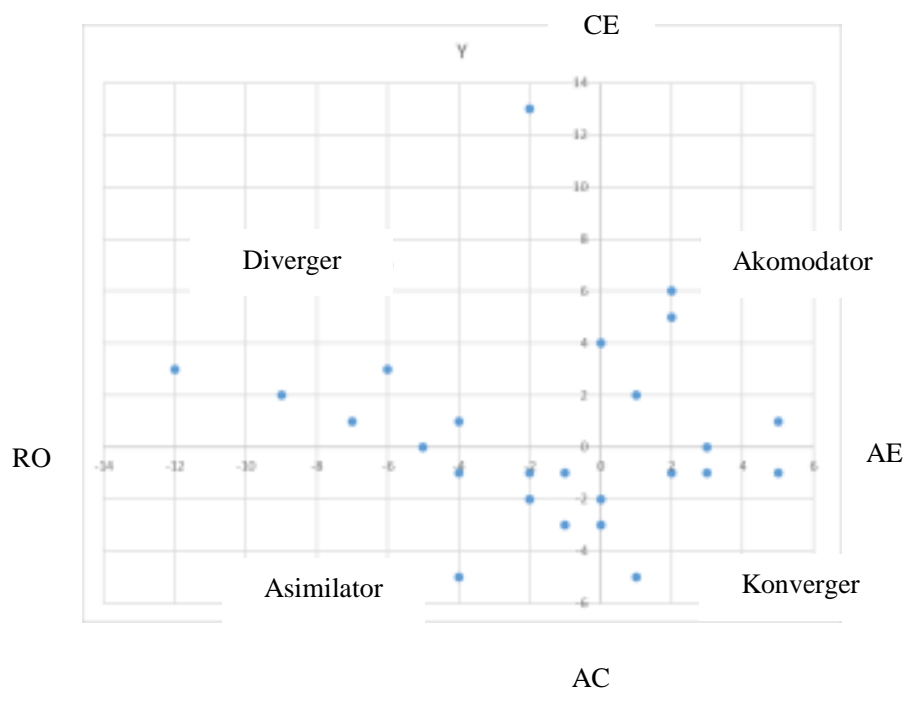

Gambar 2. Hasil Ploting Gaya Belajar Kolb pada Koordinat X dan Y

Berdasarkan gambar di atas, dapat diketahui terdapat 4 kuadran yang diisi oleh masing-masing tipe gaya belajar. Garis Y pada gambar menunjukan selisih antara aspek konseptualisasi abstrak (AC) dengan aspek pengalaman konkrit (CE), sedangkan garis $\mathrm{X}$ menunjukkan selisih antara eksperimentasi aktif (AE) dengan pengalaman reflektif (RO).

Suatu titik dapat dikategorikan ke dalam kuadran I, jika nilai Y positif dan X positif artinya memiliki gaya belajar Akomodator yang pada gambar di atas terdapat 7 titik yang terletak pada kuadran 1 artinya terdapat 7 siswa yang memiliki gaya belajar akomodator diantaranya pada titik $(0,4) ;(1,2) ;(2,5) ;(2,6) ;(3,8) ;(3,0)$ dan $(5,1)$. Suatu titik dapat dikategorikan ke dalam kuadran II apabila nilai Y positif dan nilai X negatif. Dari gambar di atas dapat dilihat bahwa terdapat 8 titik yang menempati kuadran II yang artinya terdapat 8 siswa yang memiliki gaya belajar Diverger diantaranya adalah titik $(-1,13) ;(-4,1) ;(-5,0)$; ($6,3) ;(-6,7) ;(-7,1) ;(-9,2)$; dan titik $(-12,3)$. Suatu titik dapat diketegorikan ke dalam kuadran III apabila Y bernilai negatif dan X bernilai negatif. Dari gambar di atas dapat dilihat bahwa terdapat 6 titik yang menempati kuadran III yang artinya terdapat 6 siswa yang memiliki gaya belajar Asimilator diantaranya pada titik $(-1,-1) ;(-1,-2) ;(-1,-4) ;(-2,-2) ;(-1,-3)$; dan $(-4,-5)$. Suatu titik dikategorikan ke dalam kuadran IV apabila $\mathrm{Y}$ bernilai negatif dan $\mathrm{X}$ bernilai positif. Dari gambar diatas dapa dilihat bahwa terdapat 6 titik yang menempati kuadran ke IV yang artinya terdapat 6 siswa yang memiliki gaya belajar Konverger diantaranya pada titik $(0,-2)$; $(0,-3)$; $(1,-5) ;(2,-1) ;(3,-3)$ dan $(5,-5)$. 
Adapun untuk hasil pengisisan angket diperoleh data siswa seperti pada Tabel 2.

\begin{tabular}{|c|c|c|}
\hline $\begin{array}{c}\text { Tipe Gaya } \\
\text { Belajar }\end{array}$ & Presentase & $\begin{array}{c}\text { Jumlah } \\
\text { Siswa } \\
\end{array}$ \\
\hline Akomodator & $26 \%$ & 7 \\
\hline Diverger & $30 \%$ & 8 \\
\hline Asimilator & $22 \%$ & 6 \\
\hline Konverger & $22 \%$ & 6 \\
\hline \multicolumn{2}{|c|}{ Total } & 27 \\
\hline
\end{tabular}

Berdasarkan hasil penelitian untuk angket gaya belajar siswa kelas XI IPS 1, diperoleh bahwa semua siswa menempati masing-masing tipe gaya belajar menurut Kolb. Klasifikasi tipe gaya belajar kelas XI IPS 1 paling banyak adalah tipe gaya belajar Diverger $(30 \%)$, sedangkan tipe gaya belajar yang paling sedikit adalah tipe gaya belajar Konverger (22\%) dan Asimilator (22\%).

Hal ini menunjukan bahwa siswa kelas XI IPS 1 didominasi oleh siswa yang memiliki tipe gaya belajar yang mampu melihat situasi konkrit dalam beragam prespektif dan dalam situasi formal, lebih suka bekerja dalam kelompok dan menerima umpan balik yang bersifat personal serta memiliki pemikiran terbuka.

\section{Hasil Analisis Data Kualitatif}

Hasil penelitian kualitatif didapatkan dari hasil tes kemampuan pemecahan masalah dan hasil wawancara yang dilakukan pada subjek. Hasil penelitian kualitatif digunakan untuk dapat menjawab pertanyaan penelitian tentang deskripsi kemampuan pemecahan masalah matematika siswa menurut Polya pada siswa kelas XI IPS 1 berdasarkan gaya belajar Kolb pada model pembelajaran Missouri Mathematics Project (MMP).

Subjek penelitian ini adalah delapan siswa kelas XI IPS 1 di SMA Negeri 1 Imogiri. Penentuan subjek dalam penelitian ini dengan teknik purposive sampling berdasarkan analisa hasil angket gaya belajar Kolb dan hasil tes kemampuan pemecahan masalah serta pertimbangan dari guru mata pelajaran.

Wawancara dilakukan setelah mengetahui tipe gaya belajar masing-masing siswa. Untuk setiap tipe gaya belajar, diambil dua siswa yang memiliki keunikan jawaban pada tes kemampuan pemecahan masalah, aktif dalam mengikuti kegiatan pembelajaran, serta dapat mengkomunikasikan ide maupun gagasan secara lisan dan tulisan. Adapun subjek wawancara yang terpilih ditunjukkan pada Tabel 3.

Tabel 3. Daftar Subjek Wawancara Terpilih

\begin{tabular}{cccc}
$\begin{array}{c}\text { Tipe gaya } \\
\text { Belajar }\end{array}$ & $\begin{array}{c}\text { Subjek } \\
\text { Wawancara }\end{array}$ & $\begin{array}{c}\text { Nilai } \\
\text { tes } \\
\text { KPM }\end{array}$ & $\begin{array}{c}\text { Rata- } \\
\text { rata }\end{array}$ \\
\hline Akomodator & $\mathrm{S} 6$ & 93,33 & 92,92 \\
& $\mathrm{~S} 23$ & 92,50 & \\
Diverger & $\mathrm{S} 13$ & 93,33 & 90,83 \\
& $\mathrm{~S} 16$ & 88,33 & \\
Asimilator & $\mathrm{S} 25$ & 95,83 & 92,50 \\
& $\mathrm{~S} 27$ & 89,17 & \\
Konverger & $\mathrm{S} 2$ & 90,00 & 92,08 \\
& $\mathrm{~S} 15$ & 94,17 & \\
\hline
\end{tabular}


Setiap subjek akan dilakukan analisa hasil tes kemampuan pemecahan masalah dan hasil wawancara untuk setiap tahap kemampuan pemecahan masalah, apakah indikator kemampuan pemecahan masalah pada setiap langkah pengerjaan soal muncul dan akan dikonfirmasikan pada wawancara.

Adapun identifikasi kemampuan pemecahan masalah tiap tipe gaya belajar Kolb adalah sebagai berikut:

\begin{abstract}
Akomodator
Subjek S6 : Mampu memahami masalah, merencanakan penyelesaian masalah, melaksanakan rencana penyelesaian, menarik kesimpulan.

Subjek S23 : Mampu memahami masalah, merencanakan penyelesaian masalah, melaksanakan rencana penyelesaian, menarik kesimpulan.

Diverger

Subjek S13 : Mampu memahami masalah, merencanakan penyelesaian masalah, melaksanakan rencana penyelesaian, menarik kesimpulan.

Subjek S16 : Mampu memahami masalah, merencanakan penyelesaian masalah, melaksanakan rencana penyelesaian, menarik kesimpulan.

Asimilator

Subjek S25 Mampu memahami masalah, merencanakan penyelesaian masalah, melaksanakan rencana penyelesaian.

Subjek S27 : Mampu memahami masalah, merencanakan penyelesaian masalah, melaksanakan rencana penyelesaian.

Konverger

Subjek S2

Mampu memahami masalah, merencanakan penyelesaian masalah, melaksanakan rencana penyelesaian, menarik kesimpulan.

Subjek S15 : Memahami masalah, merencanakan penyelesaian masalah, melaksanakan rencana penyelesaian, menarik kesimpulan.
\end{abstract}

\title{
Pembahasan
}

\section{Analisis Gaya Belajar Kolb}

Setelah dilakukan kegiatan penelitian di kelas XI IPS 1, dari 27 siswa terdapat 7 siswa yang memiliki gaya belajar akomodator dengan presentase $26 \%, 8$ siswa memiliki gaya belajar diverger dengan presentase 30\%, 6 siswa memiliki gaya belajar asimilator dan 6 siswa memiliki gaya belajar konverger dengan presentase masing-masing adalah $22 \%$. Penjelasan di atas menunjukkan gaya belajar diverger paling banyak dibandingkan dengan tipe gaya belajar yang lain, kemudian disusul pada posisi kedua yaitu gaya belajar akomodator, dan gaya belajar asimilator serta konverger memiliki presentase yang sama.

\section{Analisis Kemampuan Pemecahan Masalah untuk Tiap Gaya Belajar}

Kemampuan pemecahan masalah berdasarkan gaya belajar Akomodator, siswa mampu melalui keempat tahap dalam pemecahan masalah Polya yaitu: memahami masalah, membuat rencana penyelesaian, melaksanakan rencana penyelesaian, dan memeriksa kembali dengan baik.

Kemampuan pemecahan masalah untuk gaya belajar Diverger, siswa mampu melalui keempat tahap dalam pemecahan masalah Polya yaitu: memahami masalah, membuat rencana penyelesaian, melaksanakan rencana penyelesaian, dan memeriksa kembali dengan baik. 
Kemampuan pemecahan masalah untuk gaya belajar Asimilator, siswa mampu melalui keempat tahap pemecahan masalah Polya yaitu: memahami masalah, membuat rencana penyelesaian, melaksanakan rencana penyelesaian dengan baik dan memeriksa kembali dinilai cukup.

Kemampuan pemecahan masalah untuk gaya belajar Konverger, siswa mampu melalui keempat tahap pemecahan masalah Polya yaitu: memahami masalah, membuat rencana penyelesaian, melaksanakan rencana penyelesaian, dan memeriksa kembali dengan baik.

\section{KESIMPULAN \& SARAN Kesimpulan}

Adapun kesimpulan yang diperoleh berdasarkan hasil penelitian yaitu: (1) dari hasil penelitian diperoleh tipe gaya belajar Kolb pada siswa kelas XI IPS 1 dengan rincian siswa terdapat 8 siswa yang memiliki tipe gaya belajar diverger sebesar presentase $33 \%$, terdapat 7 siswa yang memiliki tipe gaya belajar akomodator dengan presentase sebesar 30\%, terdapat 6 siswa yang memiliki tipe gaya belajar asimilator dengan presentase sebesar $22 \%$ dan terdapat 6 siswa yang memiliki tipe gaya belajar konverger dengan presentase sebesar 22\% dengan demikian tipe gaya belajar diverger paling banyak dimiliki oleh siswa kelas XI IPS 1, (2) kemampuan pemecahan masalah untuk pada tipe gaya belajar akomodator, diverger dan konverger, siswa mampu melaksanakan tahap memahami masalah, merencanakan langkah penyelesaian, melaksanakan langkah penyelesaian, dan menarik kesimpulan dengan baik. Pada gaya belajar asimilator, siswa mampu melaksanakan tahap memahami masalah, merencanakan langkah penyelesaian dan melaksanakan rencana penyelesaian dengan baik, dan dinilai cukup dalam menarik kesimpulan.

\section{Saran}

Berdasarkan kesimpulan di atas, maka saran yang dapat disampaikan penulis diantaranya perlu dibiasakan pengajaran mengenai pemecahan masalah matematika kepada siswa sejak pendidikan dasar, dan bagi guru penting untuk mengajarkan pemecahan masalah matematika sesuai dengan tipe gaya belajar masing-masing siswa. Selain itu, perlu untuk dilakukan penelitian lanjutan guna untuk memperbaiki kemampuan pemecahan masalah siswa dalam memecahkan masalah matematika. Dalam hal penggunaan instrumen, perlu menggunakan alat ukur/instrumen selain angket untuk mengidentifikasi gaya belajar siswa menurut Kolb, dan perlu digunakan model pembelajaran-pembelajaran lain untuk meningkatkan kemampuan pemecahan masalah siswa.

\section{DAFTAR RUJUKAN}

Ansori, Hidayah \& Irsanti Aulia. (2015). Penerapan Model Pembelajaran Missouri Mathematics Project (MMP) Terhadap Kemampuan Pemecahan Masalah Siswa di SMP. Jurnal Pendidikan Matematika. 8(1). 49-58.

BSNP. (2006). Standar Isi untuk Satuan Pendidikan Dasar dan Menengah. Jakarta: BSNP.

Effendi, L.A. (2012). Pembelajaran Matematika Dengan Metode Penemuan Terbimbing untuk Meningkatkan Kemampuan Representasi dan Pemecahan Masalah Matematis Siswa SMP. Jurnal Penelitian Pendidikan Universitas Pendidikan Indonesia, 13 (2),110. 
Fauziah, A. \& Sukasno. (2015). Pengaruh Model Missouri Mathematics Project (MMP) Terhadap Kemampuan Pemahaman dan Pemecahan Masalah Matematika Siswa SMA N 1 Lubuklinggau. Jurnal Ilmiah Program Studi Matematika STKIP Siliwangi Bandung, 4(1): 10-21.

Garcia, T., Betts, L., Gonzalez-Castro, P., Gonzalez-Pienda, J. A., \& Rodriguez, C. (2016).On-line assessment of the process involved in maths problem-solving in fifth and sixth grade National Center for Education Statistics. (2016). Highlights From TIMSS and TIMSS Advanced 2015, Mathematics and Science Achievement of U.S Students in Grades 4 and 8 and in Advanced Courses at the End of High School in International Context. Washington DC: U.S. Department of Education.

Savitri, SN et al. (2013). Keefektifan Pembelajaran Matematika Mengacu Pada Missouri Mathemtics Project Terhadap Kemampuan Pemecahan Masalah. UNNES Journal of Mathematics Education. 2 (3). 28-33.

Sugiyono. (2017). Metode Penelitian Pendidikan Pendekatan Kuantitatif, Kualitatif, dan R \& $D$. Bandung: Alfabeta. 